\title{
POLICY ISSUES PRESENTED BY THE INTERDEPENDENCE OF COMPUTER AND COMMUNICATIONS SERVICES
}

\author{
Donald A. Dunn*
}

\section{INTRODUCTION}

The Federal Communications Commission (FCC) issued a notice of inquiry dated November 9, I966, and a supplemental notice dated March 2, 1967, to obtain the opinions of the data-processing industry, the communications industry, and various governmental and other user organizations concerning FCC Docket No. 16979, Regulatory and Policy Problems Presented by the Interdependence of Computer and Communication Services and Facilities. The FCC received over 3000 pages of responses to this inquiry from over sixty organizations. It obtained the assistance of Stanford Research Institute (SRI) in digesting and analyzing these responses, and the SRI report, which was delivered to the FCC in February 1969 , has recently been published. $^{2}$ This paper attempts to abstract some of the most important ideas from the report and to present them in a readable form, with perhaps somewhat less precision and detail than is provided in the full report. Some of the ideas presented here go beyond what is stated in the report or represent more recent formulations of its content.

- Department of Engineering-Economic Systems, School of Engineering, Stanford University, and Stanford Research Institute.

${ }^{1}$ Notice of Inquiry, 7 F.C.C.2d II (1966); Supplemental Notice of Inquiry, 7 F.C.C.2d I9 (1967). The FCC described the Inquiry's purpose as follows:

"It is the statutory purpose and responsibility of the Commission to properly regulate interstate and foreign commerce in communications so as to make available to all the people of the United States a rapid, efficient, nationwide, and worldwide communications service with adequate facilities at reasonable charges. . . [T] growing convergence of computers and communications has given rise to a number of regulatory and policy questions within the purview of the Communications Act. These questions require timely and informed resolution by the Commission in order to facilitate the orderly development of the computer industry and promote the application of its technologies in such fashion as to serve the needs of the public effectively, efficiently, and economically. To this end, the Commission is undertaking this inquiry as a means of obtaining information, views, and recommendations from the computer industry, the common carriers, present and potential users, as well as members of the interested public. The Commission will then be in a position to evaluate the adequacy and efficacy of existing relevant policies and the need, if any, for revisions in such policies, including such legislative measures that may be required. It will also cnable the Commission to ascertain whether the services and facilities offered by common carriers are compatible with the present and anticipated communications requirements of computer users. The Commission will then be in a position to determine what action, if any, may be required in order to insure that the tariff terms and conditions of such offerings are just and reasonable and otherwise lawful under the Communications Act."

7 F.C.C.2d at I $x-12$.

${ }^{3}$ D. Dunn et al., Stanford Research Institute Research Report Prepared for the Federal Communications Commission (F.C.C. Docket No. 16979, I969) [hereinafter cited as SRI Study]. 
The objectives of the SRI study of the computer inquiry were twofold: (I) to summarize and analyze the material submitted to the FCC by industry and government respondents in the proceeding, and (2) independently to analyze the issues presented by the inquiry and suggest to the FCC its principal alternatives in each case and the probable outcomes of selecting any particular one. The first objective was met by three parts of the final report, ${ }^{3}$ which included digests of all responses and analyses of these responses from two points of view. The present paper is a summary of the analysis presented in the remaining four parts of the final report. ${ }^{4}$

The basic approach to the second objective was to define the issues and the principal regulatory alternatives in each case and then to make a start on the analytical work necessary to predict the outcomes of certain specific alternative policies. In the six months allocated to the project, only relatively limited results could be obtained in this direction. The philosophy behind this approach is that decision makers such as the FCC need to be able to estimate the probable outcomes of selecting one regulatory alternative over another, in order to decide which one to select. In some cases it is, of course, simply impossible, given the present state of knowledge of economic theory and industrial behavior, to arrive at a quantitative estimate of the outcome of a particular regulatory action. However, some of the issues presented by the computer inquiry appear to have quantitative answers, and they are sufficiently important issues to merit a major investment to acquire these answers. Where more data or more analysis seems to be worthwhile, the SRI study indicates some directions that could be taken. In most cases, the respondents did not supply enough information to permit a sound prediction of outcomes to be made. Some additional data was assembled, however, ${ }^{5}$ and two analytical studies were started in directions that seem critical to further predictions in this area. ${ }^{b}$

The approach of defining the regulatory alternatives open to the FCC requires, of course, an understanding of the legal issues involved, which in this case are primarily jurisdictional. However, in this particular case the most realistic regulatory alternatives often lie well away from the jurisdictional boundaries, so that the issue is normally not whether or not the Commission has the power to act. Instead, the policy choice normally is between two alternatives that are equally valid from a legal standpoint but that may have drastically different consequences from the

\footnotetext{
${ }^{3}$ Krause, Analysis of Policy Issues in the Responses to the FCC Computer Inquiry, in I SRI STUDY, supra note 2 (Report No. 7379B-2); Lipinski, Decision Analysis of the FCC Computer Inquiry Responses, in id. (Report No. 7379B-3); Lipinski, Digests of the Responses to the FCC Computer Inquiry, in 2 id. (Report No. 7379B-5).

${ }^{2}$ Dunn, Policy Isstes Presented by the Interdependence of Computer and Communications Service, in I id. (Report No. 7379B-I); Zeidler et al., Patterns of Technology in Data Processing and Data Communications, in id. (Report No. 7379B-4); Howard \& Matheson, A Preface to a Theory of Regulation, in 2 id. (Report No. 7379 B-6); Lipinski, A Dynamic Financial Model of a Utility, in id. (Report No. 7379B-7).

ZZeidler et al, supra note 4 .

${ }^{6}$ Howard \& Matheson, supra note 4; Lipinski, supra note 4 .
} 
standpoint of the industrial users and providers of computer and communications services.

In the following sections of this paper the four major areas of concern in the computer inquiry are examined: (I) cost and quality of data communications services; (2) provision of teleprocessing services by noncarriers; (3) provision of data-processing services by communications common carriers; and (4) privacy. The conclusions and recommendations made to the FCC are given at the end of each section.

\section{I}

\section{Cost and Quality of Data Communications Services}

Perhaps the most critical issue presented by the computer inquiry is whether or not the telephone carriers are going to be capable of meeting the rapidly growing demand for low-cost data communications. Many respondents in the inquiry pointed out the rapid growth of the data-processing industry in recent years and the rapidly falling cost of making computations, both in large and medium-sized computers. One of the most rapidly growing segments of the data-processing industry is that of "teleprocessing," i.e., computer services involving the use of wire or radio communications. Any teleprocessing system involves as one of its components a data communications link, and normally this link is provided by a telephone carrier either via the public switched network as a dial-up service or via a private line provided for the exclusive use of a particular customer.

A typical example of a teleprocessing system is an airline reservations system in which a number of point-of-sale terminals are linked to a central computer that maintains a continuously updated inventory of airline seats. This type of system provides a library service to the terminals, and the content of the library is updated whenever a seat reservation is made.

The total cost of any such system comprises the costs associated with each of its four major components: computers, terminals or input/output devices, software, and communications. A major area of concern of many respondents in the inquiry may be stated as follows: The cost of a telephone line appears to have been approximately constant over the past decade, while the cost of computers has been dropping at about twenty-five per cent per year. If this trend continues, eventually the communications cost will become the dominant cost component of most teleprocessing systems. Cannot something be done to bring down the cost of a telephone line so that the present rapid expansion of the teleprocessing business can continue?

The answer to this question is not as simple as it might seem. First of all, the initial statement of fact that the cost of a telephone line has been about constant over the last decade is reasonably accurate, and the SRI projection of the future trend is that this situation will probably continue for the coming decade with perhaps a thirty per cent decrease in this period of time. ${ }^{7}$ This is a somewhat surprising result

\footnotetext{
${ }^{7}$ Zeidler et al., supra note 4 , at 72-94.
} 
when the last decade's advances in terrestrial microwave, coaxial line, millimeter waveguide, and satellite long-haul communications systems are considered. Such long. haul systems have indeed dropped the long-haul portion of the telephone line cost, and further significant reductions are expected. But the problem is that over eighty per cent of the cost, even of long-distance calls, is in the local plant, and there is very little prospect for significant cost reduction in the local telephone plant.

Second, the statement that computer costs have been dropping at twenty-five per cent per year is also reasonably correct. Both hardware and software costs have shown such a decline, when hardware cost is taken as the cost per standard computation and software cost is taken per "phrase." Some caution must be interjected at this point, however, if this trend is to be projected into the future. There is a countertrend that affects the probable cost of a teleprocessing system for a given job-namely, the tendency of customers to want systems to be made easier to use. To simplify system use requires more complex hardware, both in the computer and in the terminals, as well as more complex software. For this reason, system cost for a given function tends to fall less rapidly than the cost of a computation. Also, as communications costs rise as a percentage of the total, minimum total-system cost can often be realized with more expensive computers and terminals that do more preprocessing of the information before putting it into the communications line. The net result is a somewhat lower than twenty-five per cent per year cost reduction in the noncommunications component of typical teleprocessing systems. However, even a ten or fifteen per cent per year cost reduction is large in comparison with what is projected for telephone lines, and the basic issue remains.

Two important factors are overlooked when one utilizes the cost of a telephone line (a voiceband line) as the indicator of the cost of data communications. First, it must be realized that both the largest and the fastest growing segment of the data communications market is the low data-rate segment (less than 300 bits per second). The medium data-rate segment (300 to I0,000 bits per second) accounts for most of the remainder of the present market, and the high data-rate segment (above ten kilobits per second) is both smaller in size and lower in growth rate than the other segments, as indicated in Figure I. Since most teleprocessing terminals are for human use, and since humans are not able to make direct use of more than a low data-rate channel in most applications, the continued dominance of the market by low data-rate systems is likely to continue. An important opportunity for reduced data-communications costs in low data-rate systems lies in the sharing of a single voiceband circuit by a number of users with terminals in the same general location, such as the same building. This requires a concentrator and, if resale is to take place, a change in the legal restrictions on resale. Sharing of a voiceband circuit by several users is already possible under present tariffs.

\footnotetext{
${ }^{8}$ Id. at $26-36$.
} 
FIGURE I

Projected Number of Data Sets Connected to the Bell System Private, Message, and Wideband Data Network

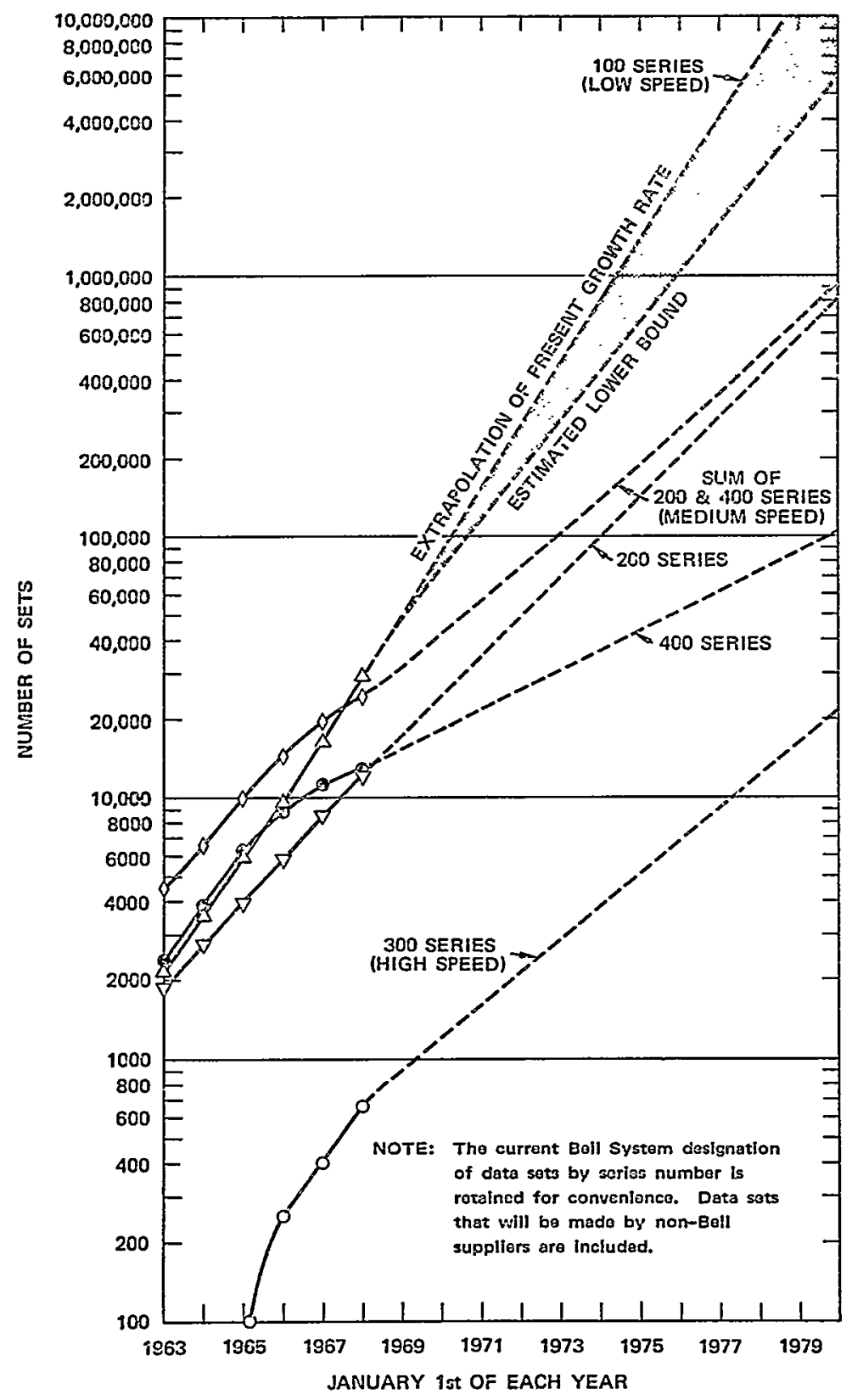

A second factor affecting the cost of data communications is the allowable data rate of a voiceband line. At present two kilobits per second is a typical value for 
the data-rate of a voiceband line in the switched network. Projections over the next decade by American Telephone and Telegraph Company (AT\&T) indicate a probable factor of four improvement in this rate, with 4.8 kilobits per second projected by 1975 . Present private lines have a higher allowable data rate than the switched network (2.4 kilobits per second), and improvement in this service is projected by a factor of four to 9.6 kilobits per second by $1975 .^{\circ} \mathrm{A}$ four to one improvement in line capacity does not result in a direct four to one cost saving because it costs more for higher data-rate terminal equipment, but the cost per bit transmitted will be greatly reduced in most systems by such an improvement in line capacity. When this factor of line-capacity increase is combined with the possibility of line sharing and resale, it appears that the cost reductions in data communications may nearly keep pace with cost reductions in the other components in teleprocessing systems.

The other major aspect of data-communications service beside cost is quality of service. A variety of new types of services are sought from the telephone companies by the data-processing industry, such as two-way lines with different data rates in each direction, error-correction capability, switched high data-rate service, and so forth. There are also delays in getting data service and equipment, especially of the newer types, in many areas of the United States. The SRI study indicated that AT\&T has made a number of major improvements in the variety of data services that are available in the last two years since the computer inquiry was initiated. Some of these new services are not yet available in all AT\&T companies, and there is likely to be a further delay before these services become available from all of the small carriers. Nevertheless, with respect to the provision of new data services, the indication is that the telephone industry is responding as effectively as can be expected, considering its size and complexity.

The data market, however, is continuing to expand, and, while it is now less than one per cent of the telephone market (measured in terminal-hours), ${ }^{10}$ it is likely to become a significant fraction of the total telephone-company business within a few years. Measured in dollars, the data market is probably more than one per cent of the telephone market now. Is it reasonable to expect that the telephone companies will be capable of acquiring the capital and assembling the new personnel needed to expand at the rate required to maintain a high quality of data-communications service? Do new incentives need to be provided to the telephone industry in order to encourage this expansion?

The principal objective of regulatory policy is the delivery of high-quality service at a reasonable cost. In a rapidly expanding business such as the data-communications field the cost of capital is one of the major components of the cost of service. In setting the allowable rate of return on invested capital, a regulatory commission wishing to minimize the cost of service will try to minimize the cost of capital to

${ }^{9}$ Id. at 66 .

${ }^{10} \mathrm{Id}$. at $69-7 \mathrm{r}$. 
the regulated industry over a period of time. To accomplish this result under conditions of rapid growth may require a new direction in regulatory policy. The present emphasis on holding the rate of return to a fixed percentage probably will need to be replaced with a different criterion of cost control. In the SRI report, two studies of the basic theory of regulation were initiated. In one study it was assumed that complete data on cost as a function of quantity and on demand as a function of price were available.11 Various regulatory policies were then tested to examine their effects on cost. In the other study a computer simulation of the financial aspects of the behavior in time of a public utility, its shareholders, its bondholders, its customers, and its regulatory agency was developed. ${ }^{12}$ Effects of changes in the allowable rate of return and in other policies were observed in the growth of the utility in the presence of various assumed demand curves. A time-sequential model of this type is needed to simulate the response of the utility to a rapidly increasing demand for its services. While both of these studies were of a preliminary nature, they suggest directions for further research that is needed in the next few years in order to decide what is the optimum financial policy for regulated industries faced with rapidly increasing demand.

The other aspect of quality of service, beside the ability to provide new types of services, is typified by quantities such as waiting time for installation of new standard-type equipment, waiting time for a dial tone, noise level on the line, and probability of getting a low-noise connection. Very little work has been done in the field of public-utility performance measurement. However, it is evident that, if any effective cost control is to be maintained or if any interutility cost comparisons are to be made, some means must be found to systematically measure performance of regulated industries. No work was done on this subject in the SRI study, but it was recommended that the FCC begin research in this field with particular reference to data communications. An objective basis might be developed for discussions between the regulatory agencies and representatives of the regulated industries concerning quality of service, if reasonable standards of quality could be devised and measurements of performance made on the basis of these standards.

It also was a recommendation of SRI that forecasting of the future demand for data communications be carried out jointly by the telephone industry, the FCC, and the data-processing industry on a continuing basis. As the industry grows and evolves it will be necessary to revise present estimates. It will also be possible to go much further in creating models of particular services and in estimating their costs than was possible in the SRI study. As the data-communications segment of the telephone companies' business increases, it will probably become feasible to make firmer predictions of the growth of particular portions of the data market. If both industries can agree-or disagree in a well-defined way-on projections of growth,

\footnotetext{
${ }^{11}$ Howard \& Matheson, supra note 4.

${ }^{19}$ Lipinski, supra note 4 .
} 
plans for expansion and new services can be measured against agreed-on projected growth.

Conclusion: It is uncertain whether or not FCC action will be required in this area. Present indications are that the rapid growth of demand for data communications may impose severe strains on the carriers in the time period starting several years from now, both in terms of capital and personnel requirements. However, there are also present indications that the carriers are preparing to meet this demand.

Recommendation: The FCC should use the time that it has to improve its information on and understanding of the data-communications field. The acquisition of forecasting and performance-measurement capabilities are two specific ways to accomplish this result. It is also important to encourage greater interchange between the data-processing industry and the telephone industry, and this forecasting activity is one way to encourage this interchange. The FCC should also make an investment in theory and modeling of the regulatory process with a view to developing criteria for optimum cost control of regulated industries under rapid growth conditions.

\section{II}

\section{Provision of Telempocessing Services by Noncarriers}

Generally speaking, the field of teleprocessing evolved from the data-processing business simply through the lengthening of the links connecting user terminals with a central computer. The minimum cost method of acquiring such extended links has been through the use of either the public switched network or private line service available from the telephone companies (carriers). Over the past decade the carriers have provided access to their network through data sets ${ }^{13}$ supplied by the Bell System and certain other manufacturers which have been matched to each type of user equipment. The basic right of noncarriers to attach their equipment to the network has not been questioned by the carriers during the past decade, and in fact the attachment of data equipment has been encouraged. The situation in data services is thus quite different from that in telephone service, where the carriers have resisted any private (noncarrier provided) attachments to or interconnections with the network. Prior to the Carterfone case, ${ }^{14}$ the carriers required that carrier-provided data sets be used to provide an interface between data systems and the network. Since Carterfone, it is possible for a data customer to provide his own modem, at least on voiceband lines, but this change is a minor one. The essential point is that, in data services other than Telex and TWX-type services, there has never been any

\footnotetext{
${ }^{13} \mathrm{~A}$ data set is the complete interface unit supplied by the carrier, including network control and signaling functions, a modem, and protective devices designed to prevent signals from entering the network that might interfere with other users. A modem is a modulator-demodulator that transforms a typical two-level (binary) computer signal into a signal suited to the telephone network. For example, a two-level signal can be converted into a two-frequency sequence of signals in the modem.

${ }^{14}$ Use of the Carterfone Device in Message Toll Telephone Service, 13 F.C.C.2d 420, aff'd on rehearing, $1_{4}$ F.C.C.2d 57 (1968).
} 
attempt on the part of the carriers to provide a complete user-to-user data service analogous to telephone service in which humans interact directly with the carrierprovided system. The portion of the system that goes between human users and the telephone network has, from the beginning, been provided by the data-processing industry.

Figures 2 and 3 illustrate these network concepts. Figure 2 is a schematic diagram of the telephone network, showing telephones connected to local exchanges which are interconnected by trunk lines. In the actual network there are five levels in the switching hierarchy rather than two as shown here. ${ }^{15}$ The entire system, including PBX units and telephones, usually is owned and provided as part of a service package by the telephone company. Figure 3 shows how the same network can be used for data processing. Only a few ways that data terminals and computers can be connected to the system have been shown. Modems are not shown, but can be regarded as part of the computers or terminals for present purposes. A line between the network and what is outside it has been shown to indicate the line drawn in Carterfone.

An important part of the telephone system is the network control signaling unit that allows the user to enter signals into the system that are used to route the call

FIGURE 2

The Switched Telephone Network as Used for Telephony

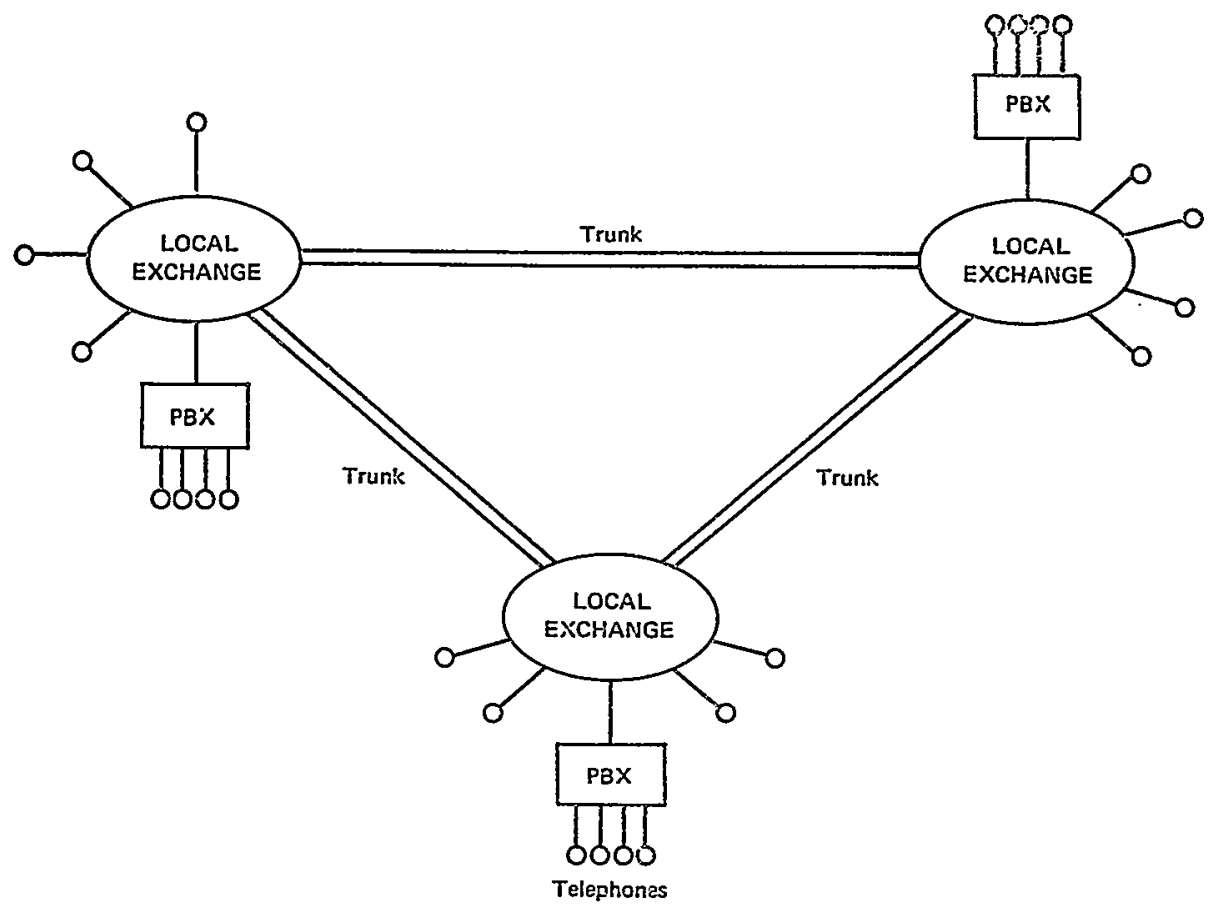

${ }^{16}$ McKay, Networks, ScI. \& TEch., April 1968, at 45-50. 
FIGURE 3

The Switched Telephone Network as Used for Data Processing

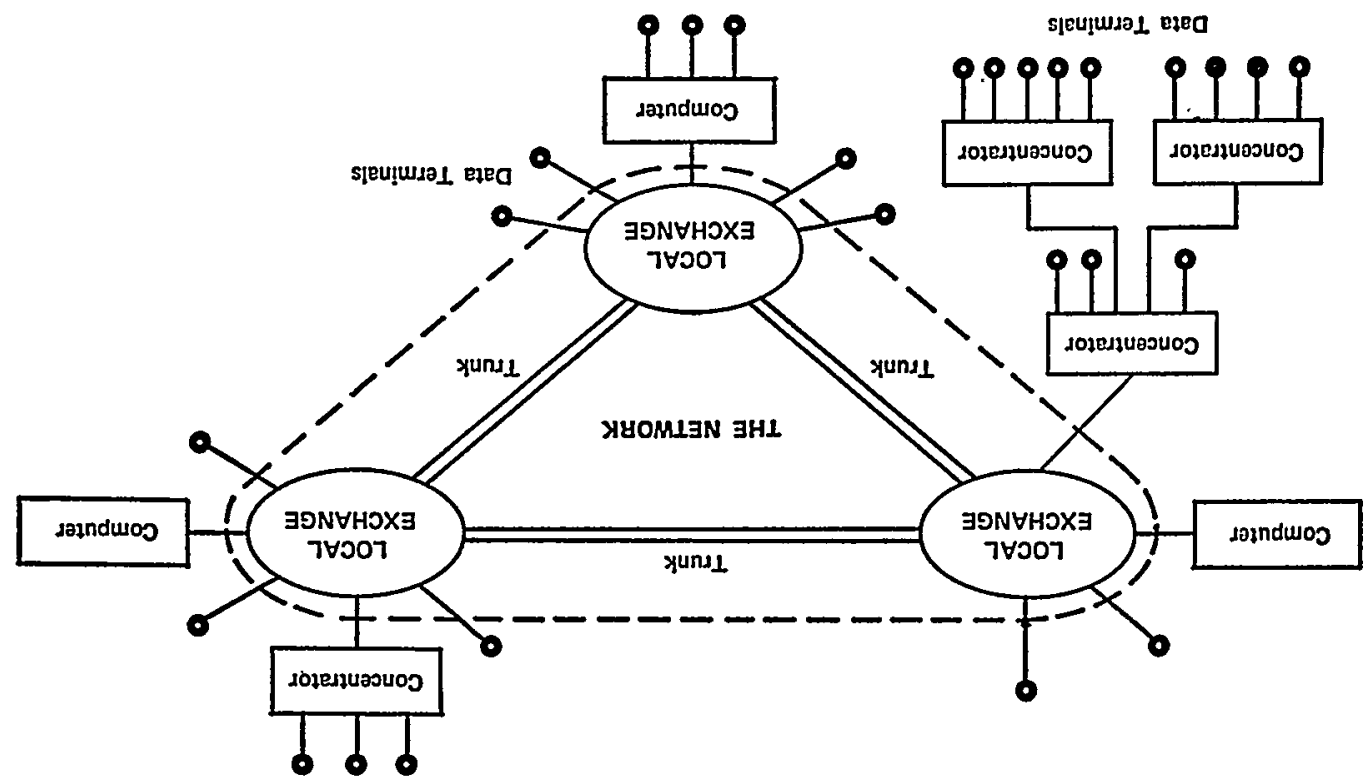

and to determine charges. The rest of the telephone instrument (the handset) can readily be conceived of as a separate unit, and it is in most telephones. We have not separately shown the network control signaling units in Figures 2 and 3, but there must be such a unit alongside, or as part of, each terminal. Figure 4 clarifies this point and shows the network control signaling unit as part of the network, as it is viewed by the carriers at the present time. Also shown as part of the network is a protective connecting attachment supplied by the carriers to protect the network against interfering signals.

There are two types of switching that are of concern in the inquiry, circuit switching and message switching. Circuit switching is the type of switching used to establish a circuit between two terminals connected to the network and is normally carried on within the network. Message switching is the type of switching used to store a particular message and then, at a later time, to forward it to one or more recipients. Typically, message switching is done in a computer external to the network. If computers exist within the network to perform circuit switching, however, they could be adapted to perform message switching. Similarly, circuit switching can be done outside the network in data concentrators which may establish a direct connection between a terminal and the line, analogous to the operation of a PBX. The traditional roles of carriers and network users in providing these classes of switching services do not seem to provide a basis for a policy of excluding either type of entity from future service offerings. 
FIGURE 4

The Boundary Between the Network and What is Outside the Network in the Case of Data Communications

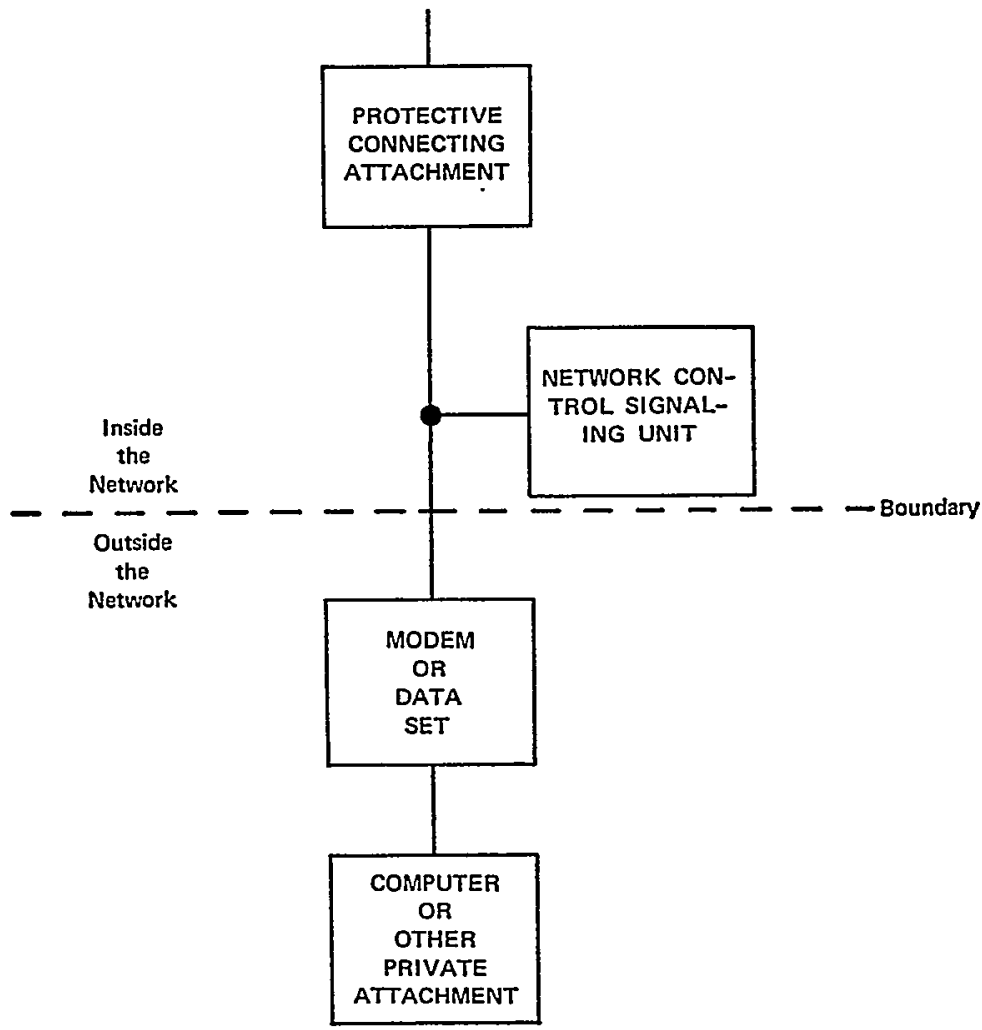

The carrier plays two quite different roles in the provision of network services to data customers and in the provision of telephone service. It offers the public a telephone-service package including as elements: the telephone directory plus directory service, the telephone instrument, use of the network, and instrument service. This package is very similar in its elements to that offered by many data processors. A data processor may offer in his service package: software, terminals, use of the network, and terminal service appropriate to the terminals offered.

This point of view, which separates various customer-service offerings (such as telephone service, remote-batch-processing computer service, credit-check service, and airline or hotel reservation service) from the provision of network service, clarifies a number of questions. It suggests the separation of regulatory questions into two categories: (I) the rules governing the physical interface between the telephone network and external equipment supplied by noncarriers, and (2) the rules governing classes of teleprocessing service that can be offered by noncarriers. 
The rules governing the physical interface are very important to the dataprocessing industry. But these rules are now in the process of being changed as a result of Carterfone and the new tariffs governing private attachments and interconnection of private networks that have followed Carterfone. These changes are precisely the ones sought by the data-processing industry as shown by many of the responses in the computer inquiry. The continuing hearings and negotiations concerning these tariffs appear to provide the proper forum for settling these rules. It cannot be expected that these rules will stay settled, but instead a continual evolution can be expected over the coming years. However, it does not appear that any Commission action, beyond its normal procedure, is called for at the present time in this area.

The rules governing classes of teleprocessing services that can be offered by noncarriers can be considered in terms of the regulatory alternatives open to the Commission. There are three theoretically possible regulatory alternatives: $:^{10}(\mathrm{I})$ regulate all teleprocessing services; (2) regulate some teleprocessing services; (3) regulate no teleprocessing services. In all cases it is assumed that the network interface, as discussed above, would be protected in such a way that the users would not be able to interfere with each other. The word regulate as used here is somewhat ambiguous. Its simplest meaning is the customary one of regulation of services, prices, and the rate of return on the services regulated. However, subalternatives exist, if we consider less than this complete package of regulatory action.

The first alternative-regulate all teleprocessing services-is only hypothetical and is not seriously considered by any of the respondents to the inquiry. It has no historical or other basis, and we do not give it further consideration here.

The second alternative-regulate some teleprocessing services-has several subalternatives, depending upon the basis on which regulated services are to be separated from unregulated services. The Sicom case ${ }^{17}$ suggested one possible criterion, that of whether or not the service is "primarily" a communications service. If it is decided that a given service is subject to regulation and can only be offered by common carriers, the question remains as to what the criteria should be for creation of new carriers and for merger with, and acquisition of, existing carriers by noncarriers. The considerations involved in this type of decision go beyond the scope of the computer inquiry, but what is decided in this area strongly interacts with the issues of the inquiry. The interest of the data-processing industry in acquiring its own data-transmission facilities is evidenced by the steps toward merger taken by Western Union Telegraph Co. and Computer Sciences Corp. ${ }^{18}$ and by the acqui-

\footnotetext{
${ }^{10}$ For a discussion of the legal aspects of regulation, see Smith, The Interdependence of Comptuter and Communications Services and Facilities: A Question of Federal Regulation, II7 U. PA. L. REv. 829 (1969).

${ }_{17}$ Western Union Tel. Co., Tariff F.C.C. No. 25I, Applicable to Sicom Service, I I F.C.C.2d I (1968).

${ }^{18}$ Western Union Telegraph Co., Proxy Statement on Proposed Merger with Computer Sciences Corp., August 1968, at 27.
} 
sition by University Computing Co. of microwave relay capability. However, the principal issue addressed here is the extent to which the unregulated dataprocessing industry can provide teleprocessing services and stay unregulated.

The third alternative-regulate no teleprocessing services-recognizes the simple fact that there are no natural boundaries between teleprocessing services. All teleprocessing services use essentially the same configuration of equipment (computers and terminals attached to the network) whether they are primarily one type of service or another. This alternative would certainly be the simplest to administer and would offer the advantage to providers of teleprocessing services that they could freely alter their service packages without fear that a slight change might bring them under regulation.

In the following paragraphs, we discuss the benefits and costs of following the third alternative versus following the second alternative posed in terms of the "primarily communications" test. Note that if the only area subject to regulation is that suggested in Sicom, there is probably no jurisdictional problem, because if a service is "primarily communications," it would fall within the terms of the Communications Act. ${ }^{19}$ If the third alternative is followed, there is obviously no jurisdictional problem; the Commission need not regulate everything within its jurisdiction.

Increased Competition. The essential benefits associated with free entry are the traditional ones associated with increased competition: improved and more diverse service offerings and lower prices. In this industry, where we have already seen a remarkable growth and diversity in the technology that has been developed by the data-processing industry, the potential benefits of free entry into the entire teleprocessing area appear to be substantial. The services in which benefits will be experienced from this alternative will be those that are primarily communications services. The potential for a wide range of communications services that are neither telephone nor telegraph is very large, and the technology that could make these services widely available is rapidly coming into the cost range of interest. The effect of lower prices often accompanies changes in services. It is not just a matter of making equipment more cheaply than Western Electric as a result of increased competition (which is probably an unlikely possibility). Much more likely is the development of new lower-cost services that are just as useful to some users as more expensive existing services of various types.

Loss of Interconnection. The principal cost of opening up teleprocessing services that are primarily communications to unregulated competition is the potential loss of interconnection among users. There is a benefit experienced by all users of a network simply as a result of being able to exchange messages with the other interconnected users. If the size of the network is decreased as a result of the development of a competitive network, there is a loss of interconnection. In the present

\footnotetext{
${ }^{10}$ Communications Act of I934, 47 U.S.C. $\$$ I5I et seq. (I964).
} 
situation, this cost may or may not exist. If competition results in greatly lowered costs, then even if there were several networks for say Telex-TWX-type services, each network might become larger than the present one, and the degree of interconnection might actually increase. However, this is speculation.

An important regulatory subalternative exists that could eliminate this potentially important cost and yet obtain the benefits of competition in at least some communications services. This subalternative is to allow free entry of noncarriers into teleprocessing, including areas that are "primarily communications," provided that interconnection can be maintained through the development of standards of technical performance and of signaling and message format that would make directly competing systems compatible. Such standards could in some cases impede the development of competing lower-cost systems. However, a competitive system with standards would almost certainly provide a more competitive environment than a carrier monopoly, which is the other major alternative that guarantees interconnection. In some cases standards could be developed cooperatively by the system providers. In others it would be necessary to require that new entrants meet standards determined by the system used by the dominant system provider. Requiring compatibility with the dominant existing system avoids the necessity either for getting agreement among competitors or for the regulatory agency's getting into technical design. Even so, there are difficulties in such a course of action, particularly with respect to changing the standards as new technology becomes available that can offer economies of service only under new standards.

Cream-skimming. If some types of data-communications services were allowed on an unregulated basis, they would compete directly with existing carrier network services. For example, if interconnection of private networks is allowed, as is the case under Carterfone, it will be possible to supply microwave links between two points and obtain interconnection with the carriers at both ends to the users' terminals. If resale is allowed, a competing "carrier" would be created. Naturally such a "carrier" would only wish to operate in the most favorable markets, and he might prefer not to have to supply all users on the same basis. For example, if his system became fully used he would not wish to add customers until he could be fairly certain that there would be enough additional customers to pay the next increment in cost to add the next increment in capacity. True common carriers object to this type of competition as cream-skimming, and point out that if they lose high-profit markets to cream-skimmers, they will have to raise rates for the low-profit portions of their markets, thus resulting in a loss of service to some areas of the country or to some classes of marginal users. While this argument can be a valid one, in any particular case it is important to determine whether or not the argument applies to the particular service in question and, if it does, whether or not the existing cross-subsidization is desired. In some cases the degree of cross- 
subsidization between markets that the carrier will be forced to discontinue may not be significant. In others it may not even be desirable.

In the case of purely data-communications service, there may not be the same concern for providing services to all parts of the United States at uniformly low rates that exists in the case of telephone service. It is probably more appropriate for price differentials to reflect cost differentials in this field than is the case in telephone service. A company that locates near a freeway is prepared to pay a high price for land in order to obtain good access to transportation. The same philosophy should apply to data communications, and the Commission probably should not attempt extensive equalization of prices through cross-subsidization of data markets. The cream-skimming argument is therefore not a strong one as applied to noncarriers seeking to provide purely data services. If noncarriers seek to provide combinations of data and telephone services, however, the cream-skimming factor could become important.

Conclusion: The benefits of permitting increased competition in teleprocessing services probably outweigh the costs of such a policy, even in services that are primarily communications, especially if loss of interconnection can be avoided through the establishment of technical standards that assure compatibility among directly competing systems.

Recommendation: Allow free entry into all teleprocessing services by noncarriers, provided ( $I$ ) there is no interference with other users of the network, and (2) loss of interconnection can be avoided through the development of technical standards that allow directly competing systems to be interconnected.

\section{III}

\section{Provision of Data-Processing Services by Communications Common Carriers}

Easily the most controversial issue in the computer inquiry is this: Under what circumstances (if any) should telephone and telegraph companies regulated by the FCC and the state commissions be permitted to offer data-processing services to the public? Although it is possible that the carriers might seek to compete with data processors in a wide range of data services, the principal area of concern is the teleprocessing type of service which would make use of the carriers' own communications network.

There are several reasons why the carriers might prove to be formidable competitors in the teleprocessing area. First, they have a detailed technical knowledge of their own plant which might allow them to develop some unique teleprocessing systems technology and to achieve some systems economies not evident to noncarriers. Second, they would have the opportunity to make managerial innovations arising out of their control of the total system. Integration of the carriers' own business information systems with their network and offering of this class of service to the business community as a whole is a potential example. There are some rather less 
likely possibilities for utilizing the carriers' future switching computers in data processing. There would probably be a number of real opportunities for developing integrated teleprocessing systems that the carriers could exploit more readily than any noncarrier organization. Third, the carriers have a marketing advantage over the data-processing industry in that they already supply telephone service to every potential teleprocessing customer, and they thereby have easy access to all these potential customers.

All of the above advantages are legitimate business advantages that might lead to the offering of teleprocessing services by the carriers at a lower cost to the customer than could be met by the existing data-processing industry. If this were all there were to the situation, it is quite likely that the commissions would allow the carriers to enter this field without further ado. However, there are other potential advantages that the carriers possess that are not legitimate business advantages. These are advantages arising out of the legal monopoly that the carriers possess in the field of telephone and telegraph service. There is a deeply felt concern in the data-processing industry that the carriers are likely to sell teleprocessing services below cost and recover the losses so incurred from their monopoly business. The carriers could utilize this tactic without loss to themselves, because they can maintain their telephone prices at a level that will cover their losses and still stay within the profit constraint set by the regulatory commissions. Such conduct would be considered as predatory pricing, and as such it violates several antitrust statutes. Probably clearly visible conduct of this sort would be deterred by the threat of trebledamage suits. However, it may not be necessary for the carriers to do more than meet the prices of the competition and to accompany their offerings with, for example, somewhat better maintenance and repair service than their competition, in order to take over a large fraction of the teleprocessing market. In such a case it would be extremely difficult to ascertain whether the services offered by the carriers were being offered at a loss or not, because of all the joint costs involved in the accounting between teleprocessing and telephone services.

It is primarily for the reason that it is difficult to determine the cost of a specific service, both for the carriers and for their potential competitors, that it is appropriate to consider either an absolute prohibition of carrier entry into data processing or a carefully devised set of safeguards designed to force the carriers to make their costs visible. An absolute prohibition would be easy to administer and would meet with an enthusiastic reception by the data-processing industry. An adequately safeguarded system is not easy to devise. Respondents in the computer inquiry suggested as alternatives separate books and also the requirement that the carriers establish separate data subsidiaries.

Separate books would have the additional advantage of reducing to some extent the regulatory complications that diversification would be bound to create, but it would not be a complete answer to the problems of predatory pricing. Account- 
ing categories are inherently arbitrary and manipulable, especially where joint or common costs are involved. Although various methods exist to prevent completely improper allocations, a wide range of discretion is unavoidable. Nor can the difficulty be overcome by requiring that the carriers form separate corporate subsidiaries to provide data-processing services. Such an arrangement would replace accounting separations by contractual arrangements between carrier and dataprocessing subsidiary, but the terms of the contract would be as arbitrary and manipulable as if the relationship were frankly intracorporate. So long as the dataprocessing and communications functions are commonly owned and there are significant elements of operational integration, a clean separation of costs and profits is simply impossible.

This difficulty has led some to suggest limitations on dealings between a parent carrier and its data-processing subsidiary. ${ }^{20}$ One type of restriction would be to bar the separate affiliate from selling data-processing services to the carrier. This would assure that sales of such services (which do not necessarily involve published prices) are not used as a disguised subsidy by the carrier of the affiliate's competitive activities in the nonregulated sector. The parent carrier would also have to be forbidden to sell or lease computer or other facilities to its subsidiary, if cross-subsidization of this type is to be avoided. And if it sold communications services to its subsidiary it would either be required to sell at the same prices and under the same conditions that it would sell to others, or possibly it would be barred from selling to its subsidiary altogether. "Total separation" has some precedent in the common-carrier field, in that a railroad is prohibited from transporting on its own lines any goods which it owns or in which it has an interest. ${ }^{21}$ But whatever merit this limitation may have in the case of rail carriage, it seems clearly inappropriate for data-processing and communications carriers. The fundamental justification for permitting carriers to enter the field would be to enable the realization of whatever economies may result from an integrated communications/data-processing service. To bar such economies by requiring complete separation of parent and affliate, therefore, offers little improvement over absolute prohibition of entry.

Western Union is a special case, in that it has no large pool of monopoly profits from the telegraph business that it would be able to divert to cover losses in teleprocessing. On the other hand, it has a special position in relation to other carriers that allows it to obtain reduced rates from them. An appropriate safeguard with respect to Western Union would therefore be to condition approval of its entry into teleprocessing on submission of its intercarrier contracts for approval and possible revision to assure fair competition with teleprocessors subject to the telephone carriers' ordinary tariffs.

\footnotetext{
${ }^{30}$ Response of the Justice Department at 8o-82, Regulatory and Policy Problems Presented by the Interdependence of Computer and Communication Services and Facilities, No. 16979 (F.C.C., May I, r969).

${ }_{21}$ Interstate Commerce Act, 49 U.S.C. $\S$ I(8) (1964).
} 
General Telephone and Electronics Corporation has recently formed a dataprocessing subsidiary (GT\&E Services Corporation), and approval of its entry into contracts and other relationships with its carrier affliates could be conditioned on full disclosure and the development of a convincing set of safeguards. Of considerable importance would be the threat of removal of authorization if abuses were to develop, and some means for objectively determining whether or not abuses in fact occur would be an important part of a plan for authorization.

$A T \& T$ and its subsidiaries are in a special position as a result of the Western Electric consent decree, which prohibits "noncarrier" activities. ${ }^{22}$ However, whether or not teleprocessing is a carrier-type activity is precisely the issue presented here. $A T \& T$ has disclaimed any intention to enter the data-processing field. Yet it is the carrier that is most likely to be able to offer savings to teleprocessing users as a result of integration of technology and management. And it is also the carrier most capable of utilizing monopoly profits to subsidize its teleprocessing activity simply because it has such vast profits as a result of its size.

Conclusion: Present information on, and models of, industrial behavior are not sufficient to allow a valid prediction to be made of the outcome of allowing the carriers to enter data processing. While there is no real necessity for allowing them to enter the field, as the area is highly competitive already, there is the possibility of cost savings to users arising out of an integrated approach to teleprocessing that is only possible for the carriers.

Recommendations: As remarked in one review of the SRI study, ${ }^{23}$ the only clear message that can be given to the FCC in this situation is, "You fellows have a problem here." SRI did recommend that, if carriers are allowed to enter the dataprocessing field, they should be required to make an affirmative showing that they have devised an adequate approach to the problem of making their costs visible. If it is decided to allow the carriers to enter data processing on a trial basis subject to safeguards that are worked out with the carriers, special measures should be taken to gather independent information on what actually does happen. A development of measures of carrier performance would be extremely relevant if both benefits (if any) of integration and fairness of carrier competitive practices were included in the measurements.

\section{IV}

\section{Prrvacy}

The computer inquiry included as its final question, "What measures are required by the computer industry and common carriers to protect the privacy and proprietary nature of data stored in computers and transmitted over communication facilities, including

\footnotetext{
${ }^{22}$ United States v. Western Elec. Co., I956 Trade Cas. 7r,r34 (consent decree filed Jan. 24, x956, D.N.J.)

${ }^{28} 35$ Telecomanunications Rep. No. 20, May I2, 1969.
} 
(घ) Descriptions of those measures which are now being taken and are under consideration; and

(2) Recommendations as to legislative or other governmental action that should be taken."

The respondents to the inquiry described a number of technical and procedural measures now being taken and under consideration. They also suggested a variety of governmental actions that might be taken, including actions by the FCC and actions by state governments. These measures and actions are summarized in the SRI report.

There are two broad classes of problems in the privacy area. ${ }^{24}$ One class of problems has to do with industrial espionage and generally with the gaining of unauthorized access to data. The other has to do with the rights of individuals concerning whom data is assembled in various types of central data files such as credit information systems. Should individuals be given the right to see what data is on file concerning them? Should they have the right to institute proceedings to correct the information on file concerning them? These problems will become increasingly important as we move into the "checkless society." Issues of this type, while affected by the development of teleprocessing, transcend the issues of this inquiry and probably should be dealt with on a broader basis.

Issues arising when individuals gain unauthorized access to central data files and other proprietary sources of information involve both individual and industrial users of teleprocessing systems and data-processing systems generally. In both teleprocessing systems and in data-processing systems generally there are many ways of gaining unauthorized access to data. Three basically different problems are presented by persons gaining access ( $I$ ) through the employees of the user or the system manager; (2) through use of the proper coded access signals acquired by improper means; or (3) through wiretapping and related techniques. Obviously this is not a problem that will have absolute answers. It is reminiscent of electronic warfare in which any given measure aimed at protecting a system has a countermeasure. The object of the game is to raise the cost of unauthorized access to a level at which only an acceptable loss of privacy occurs. This is a game that primarily takes place between users of the system and their competitors. Thus this portion of the inquiry is of much less direct concern to the carriers and the data-processing industry than it is to their customers, such as the banking industry.

As in the other aspects of teleprocessing, the technology that affects this part of the system is changing rapidly. Certain techniques that could provide greatly

\footnotetext{
${ }^{24}$ Baran, The Coming Computer Utility-Laissez Faire, Licensing or Regulation, THE PUB. INTEREST, Summer 1967, at 75; Does the Interconnected Computer Network Pose a Hidden Threat of Invasion of Privacy?, Hearings on the Computer and Invasion of Privacy Before the Subcomm. of the House Comm. on Government Operations, 8gth Cong., 2d Sess. II9-35 (I966); A. Harrison, The Problems of Privacy in the Computer Age: An Annotated Bibliography (I967). For a recent discussion of this subject, see Miller, Personal Privacy in the Computer Age: The Challenge of a New Technology in an InformationOriented Society, 67 Mich. L. REv. I09I (1969).
} 
increased privacy at reasonable costs are likely to become available within a few years. In the area of providing increasingly complex access codes, the concept of computer-aided voice recognition appears promising, but it is not now available. In a teleprocessing system, wiretapping is as simple as it is in the telephone system generally, and here the basic countermeasure is encryption. The cost of encryption is falling along with the cost of computation, but so is the cost of decoding.

Conclusion: At the present time there does not seem to be a great deal of pressure being placed upon the teleprocessing industry by its customers to provide privacy. Nor does this industry appear to be interested in making this an area in which competitive advantage is sought. The issue before the Commission is whether or not it should seek to create further incentives for the data-processing industry and for the carriers to maintain user privacy. It is reasonable to expect users interested in privacy to have to pay extra for it, but it is important to make certain that reasonable options are available. It does not appear that a user who presently wishes to buy extra privacy has very significant options open to him in most systems.

Recommendation: In view of Congressional concern in this area and the likelihood of legislation that would affect the data-processing industry generally, it appears that the most significant area for Commission action at the present time would encompass those aspects of the problem unique to teleprocessing and telecommunications. It would be important as a first step to examine present carrier practices and procedures, both with respect to data and voice. A study of the costs of obtaining increased privacy in teleprocessing and in the use of the telephone network generally could provide a basis for further action in the future in support of Congress. 